Article

\title{
Analyzing the Value and Evolution of Land Use Functions from "Demand-Function-Value" Perspective: A Framework and Case Study from Zhangjiakou City, China
}

\author{
Chao Liu ${ }^{1}$, Yueqing $X u^{2}$, Yue Wang ${ }^{3, *}$, Long Cheng ${ }^{4} \mathbb{D}$, Xinhai Lu ${ }^{1}$ and Qingke Yang ${ }^{5}$ \\ 1 College of Public Administration, Central China Normal University, Wuhan 430079, China; \\ chaoliu@ccnu.edu.cn (C.L.); luxinhai@hust.edu.cn (X.L.) \\ 2 College of Land Science and Technology, China Agricultural University, Beijing 100193, China; \\ yqxu@cau.edu.cn \\ 3 College of Public Administration, Zhongnan University of Economics and Law, Wuhan 430079, China \\ 4 School of Political Science and Public Administration, Shandong University, Qingdao 266237, China; \\ 1.cheng@sdu.edu.cn \\ 5 School of Public Administration, Nanjing University of Finance \& Economics, Nanjing 210023, China; \\ 9120181073@nufe.edu.cn \\ * Correspondence: wangyue@zuel.edu.cn
}

check for

updates

Citation: Liu, C.; Xu, Y.; Wang, Y.;

Cheng, L.; Lu, X.; Yang, Q. Analyzing the Value and Evolution of Land Use Functions from "Demand-Function -Value" Perspective: A Framework and Case Study from Zhangjiakou City, China. Land 2022, 11, 53. https://doi.org/10.3390/land 11010053

Academic Editor: Volker Beckmann

Received: 30 November 2021

Accepted: 28 December 2021

Published: 30 December 2021

Publisher's Note: MDPI stays neutral with regard to jurisdictional claims in published maps and institutional affiliations.

Copyright: (C) 2021 by the authors. Licensee MDPI, Basel, Switzerland. This article is an open access article distributed under the terms and conditions of the Creative Commons Attribution (CC BY) license (https:// creativecommons.org/licenses/by/ $4.0 /)$.

\begin{abstract}
Understanding land use functions (LUFs) value is critical for implementing sustainable land resources management and optimizing territorial space in China. However, existing research insufficiently portrays the contributions of land use to economic activity and people's well-being. To address this crucial absence, this paper attempts to clarify the connotation of LUFs' value and the logic of LUFs' optimization under the national territorial space planning system by applying the "demandfunction-value" integrated framework. Based on this framework and taking Zhangjiakou City as a case study, we classified LUFs into economic, social, and ecological functions. Then, we assessed the monetary value of LUFs at the grid level using spatialization and environmental economics methods. Besides, we analyzed the evolutionary characteristics of LUFs and their diversity and dominance. The results showed that the total value of economic, social, and ecological LUFs increased continuously between 1990 and 2015. Spatially, the ecological function showed an opposite pattern to that of social and economic functions. Additionally, the dominant role shifted from ecological function to social function, and the dominant functional combination changed from ELP-ENS-ST to SP-ENS-ELT over this period. Lastly, this paper proposes that policymakers identify and optimize ecological-production-living space through LUFs' value assessment and coordination. The results provide a new methodological insight into the assessment and coordination of LUFs and adaptive land use management.
\end{abstract}

Keywords: land use functions; humanity demand; economic value; ecological-production-living space; Zhangjiakou City

\section{Introduction}

The available spatial territory for human activities is very limited, confined by strict restrictions of resources and environment. Accelerated urbanization and industrialization have promoted the continuous large-scale development of land resources, causing ecological space shrinkage, atmospheric pollution, and land degradation [1]. This situation is more severe in developing countries, particularly in China. The synergy between socioeconomic development and ecological protection has been the heart of sustainable development research in China [2]. The national territorial space is composed of land use functions (LUFs) [3]. The conflicts in LUFs are responsible for the disorderly exploitation of territorial space and the degradation of the land system. LUFs can be regarded as public 
or private goods and services produced by land use activities [4-6], aiming at establishing a harmonious relationship between nature and humans through multifunctional land management. Therefore, optimizing national territorial space is considered the primary measure of constructing an ecologically sound human civilization [7]. LUFs research is a vital issue in the optimal development of national territorial space.

LUFs assessment is essentially the evaluation of different kinds of land use to provide products and services. LUFs are initially measured by the land use type merging (LUTM) method, which integrates land use types that possess the same functions $[8,9]$, but it cannot accurately describe the importance of socioeconomic factors. Thus, comprehensive appraisal method (CAM), such as the entire-array-polygon (EAP) indicator method [10], the triangle model [11], and the polygon synthetic graphic method [12], based on the construction of an index system from statistical data, have been popular in calculating a functional index for characterizing LUFs [13]. However, CAM assessment of LUFs is not detailed enough for spatial information. Given the above shortcomings, the multisource data fusion (MSDF) method, which integrates land use, geospatial, socioeconomic, and ecological data, has been proposed to measure LUFs from a spatial, eco-social, and ecological integration perspective $[6,14]$. LUFs are various benefits that humans derive from the interaction of biological and human production [15]. LUFs are valuable for condensing human society's necessary labor into the land use process. However, the MSDF method does not comprehensively present land resources' economic and social contributions using simply biophysical measures [16]. In general, CAM and MSDF are unable to integrate a vast amount of economic information intoLUFs assessment process, resulting in a failure to reflect LUFs' value. Moreover, it is worth considering whether LUFs' value can be measured in a money metric.

Some scholars have attempted to measure the value of land ecosystem services, providing a theoretical basis and methodological reference for assessing LUFs' value. For example, Constanza et al. (1997) [17] estimated the value of global ecosystem services. Bernués et al. (2014) [18] elucidated the sociocultural and economic value of mountain agroecosystems' services in Euro-Mediterranean regions. Hou et al. (2019) [19] explored the spatiotemporal variation of the ecological service value for different land use types in Yan'an. However, the available studies focus more on the ecological goods provided by natural ecosystems and less on the economic and social goods produced by eco-social systems. Therefore, it is urgent to develop a methodology for valuating land products and services that present LUFs value for capturing the internal logic between land use and economic development.

Since the conceptual framework of LUFs was established as an essential tool for evaluating regional sustainability, researchers have made explorative studies of the concept, connotation, classification, and characteristics of LUFs. For example, Pérez-Soba et al. (2008) [4] studied the concept and category of LUFs from sustainability aspects. Liu et al. (2018) [15] defined LUFs within a conceptual framework of structure, function, and wellbeing. Wang and Zhen (2017) [20] comparatively assessed LUFs given the feedback from perceptions of policymakers and local farmers. Based on the relevant theoretical research, some scholars studied the quantity and form of LUFs [21,22], spatiotemporal changes, and the factors affecting LUFs [23-26], the trade-offs among multiple LUFs [11,27], as well as LUFs' zoning [28,29]. It is important to note that identifying the diversity and dominance of LUFs is an important avenue for a comprehensive status assessment of national territorial space and the extent to which it meets human aspirations and socioeconomic development. However, existing studies failed to discern dominant functions of national territorial space limited by visual comparability between different LUFs. In this context, the characteristics of LUFs still need to be investigated from diverse and dominant perspectives, which will facilitate spatial optimization of the territorial space.

Given these considerations, the existing research failed to capture fully the value attributes of LUFs, and the evolution of its diversity and dominance. Therefore, this paper attempts to assess LUFs value and their evolution characteristics by applying the 
"demands-function-value" integrated framework. Specifically, taking Zhangjiakou as a case study, this research aims to:

(1) Present the logic of formation of LUFs' values, as well as set out a valuation methodology;

(2) Measure and map the value of land use economic, social, and ecological functions employing monetary metrics in Zhangjiakou City;

(3) Analyze the evolution characteristics of LUFs, and the combination and dominance of LUFs in Zhangjiakou City between 1990 and 2015;

(4) Provide scientific references for coordinated improvement for LUFs in Zhangjiakou City.

\section{Analytical Framework for Valuation and Evolution of LUFs from the "Demand-Function-Value" Perspective}

The formation and realization of value require the orderly cooperation of production, allocation, exchange, and consumption in the operation of the economic system [30]. LUFs are the economic and natural outputs of land resources under the continuous or periodic interference of human demands and their consequent activities [30,31]. We developed the "demands-function-value" integrated framework to identify and assess LUFs' value, as shown in Figure 1. The framework comprehensively evaluates the relationship between LUFs and human well-being. Land system is incredibly dramatically complex and influences people's well-being in diversified approaches. Land use is the exchange of energy and information between humans and the land itself and the input of certain types of labor to the land. Indeed, these labor inputs, such as materialization and monetary capital, result in land use being a means or process of capital multiplication. Different land use types/structures are formed after natural evolution or labor input to meet human demands. LUFs, i.e., tangible goods and intangible services, are generated by these interactions of land use types/structures according to the system theory that structuredetermines function [15]. As a result, LUFs are the materialized or monetary capital condensed in land use arising from social labor, which has the dual attributes of production of raw materials and labor products.

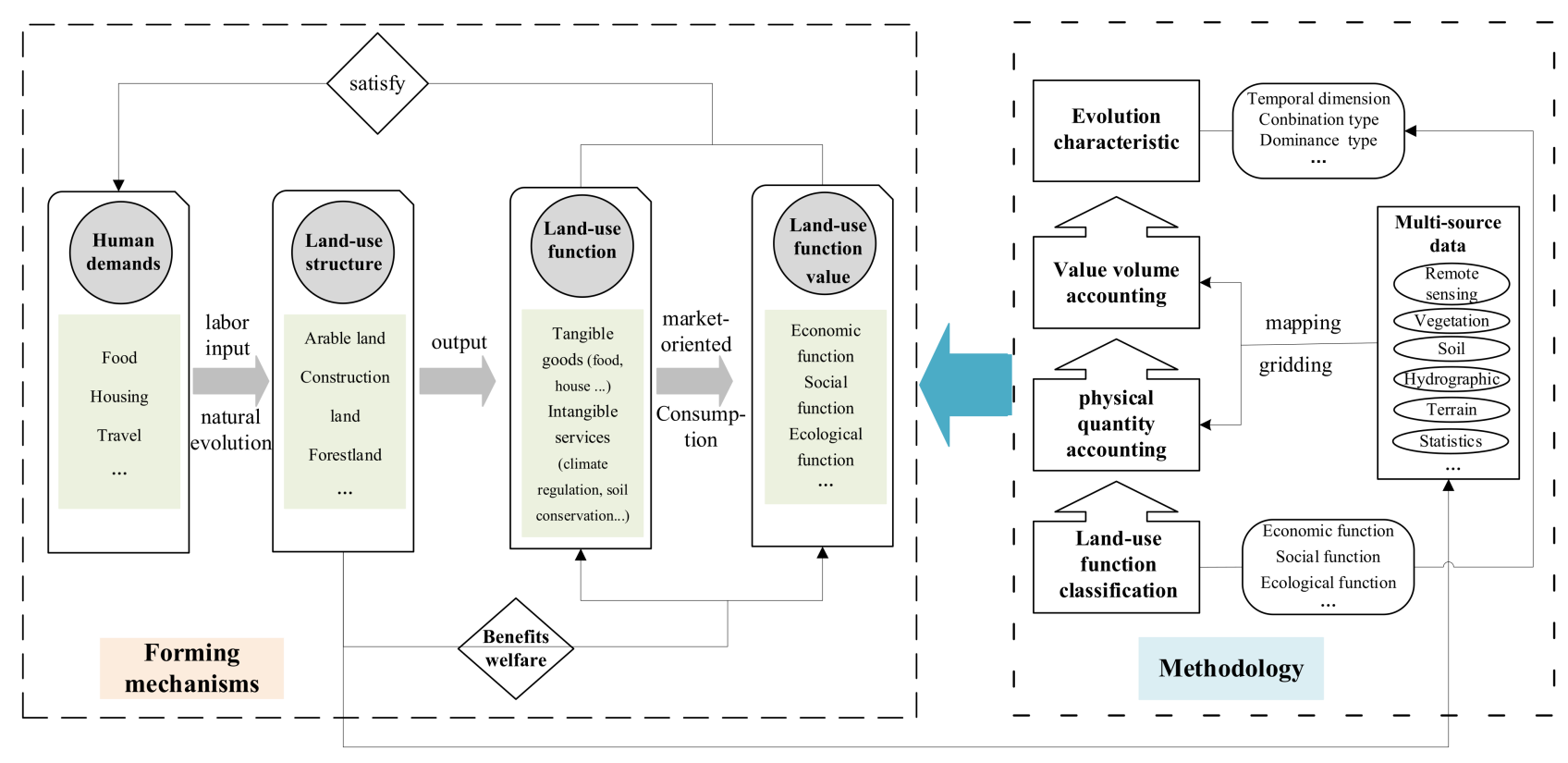

Figure 1. The analytical framework for analyzing LUFs value and their evolution.

In summary, LUFs derive economic value (commodity value) through being used and consumed by human populations. Therefore, LUFs' value concept emphasizes the following aspects: (1) terminal products. They are specific, visible, and measurable results produced by land use system processes, directly related to specific human benefits. 
(2) Market transactions. LUFs' products are the result of human exploitation, protection, and operation that can reflect labor value. Therefore, the products can be exchanged in the market. (3) Human consumption. The core of products is the usefulness and can meet people's certain needs. The purpose of LUFs' production is to satisfy the increasing expectations of people for a high-quality life. The land use system provides well-being and is used and consumed by human beings.

Land use economic function means the economic value of land use and related contributions to meeting residents' needs for exchanging goods and services and boosting the local economy [15]. Social function indicates land use provides adequate food and places for people's general demands for survival and further development, while ecological function relates to the raw materials and survival space offered by the natural environment, ecological resources, and ecosystem products [14,31]. Economic valuation (monetization) of LUFs is a monetary measure of functional utility, expressed as the market value or social cost of tangible products and invisible services. Furthermore, they can be measured by the market price. Thus, this paper integrates multisource data and environmental economics methods to assess LUFs' value quantitatively.

The economic valuation flow of LUFs includes the classification, physical quantity accounting, monetary value accounting, and characteristic evolution analysis of LUFs. LUFs' classification, as the basis of economic valuation, is analyzed by generalizing and abstracting the data for LUFs to determine the specific evaluation object [32]. Physical quantity accounting objectively reflects the capability of land use supplying products and services. Hence, based on remote sensing, meteorology, hydrology, statistics, and land use data, the physical quantity of LUFs is calculated through mathematical models and a spatial discretization method. Monetary value accounting reflects the value placed by human society on land use to provide products and services. Consequently, the monetary value of LUFs is calculated based on physical quantity accounting by indirect or direct market methods. The analysis of evolution characteristics, including changes in diversity and dominance of LUFs, reveals the external appearance and internal laws relating to changes in LUFs value.

\section{Data and Methods}

\subsection{Case Study Area}

Zhangjiakou City is placed in the northern Hebei Province with $3.68 \times 10^{4} \mathrm{~km}^{2}$, including the Bashang Plateau and the Baxia Hills Basin (Figure 2). Zhangjiakou City has created agricultural specialty industry, mining and metallurgy, and equipment manufacturing. Moreover, Three-North Shelterbelt and Grain for Green and other programs have been carried out to halt land degradation and soil erosion. In recent years, the city has been undergoing coordinated development of the Beijing-Tianjin-Hebei region and the joint host city with Beijing for the 2022 Winter Olympics. The fact will, on the one hand, increase the need for construction on land; on the other hand, encroach on both agricultural and ecological land.

With the conviction that unpolluted waters and flourished mountains are priceless assets, more attention is increasingly being paid to the value of land resources. The city is a national-level demonstration ecology zone, and its overall ecological environment is fragile. To develop the economy and meet human needs while protecting ecology requires a value assessment of land use and its products. Thus, analyzing the value and evolution of LUFs will support the ecological protection and supply of special agricultural products in Beijing-Tianjin-Hebei and even the whole country. For these reasons, we have taken Zhangjiakou City to conduct an empirical analysis of LUFs' value assessment, which is typical and representative. It is of practical significance to promote the harmonious development of economy and ecological environment and to realize the construction of ecological civilization in Zhangjiakou City and similar areas. 


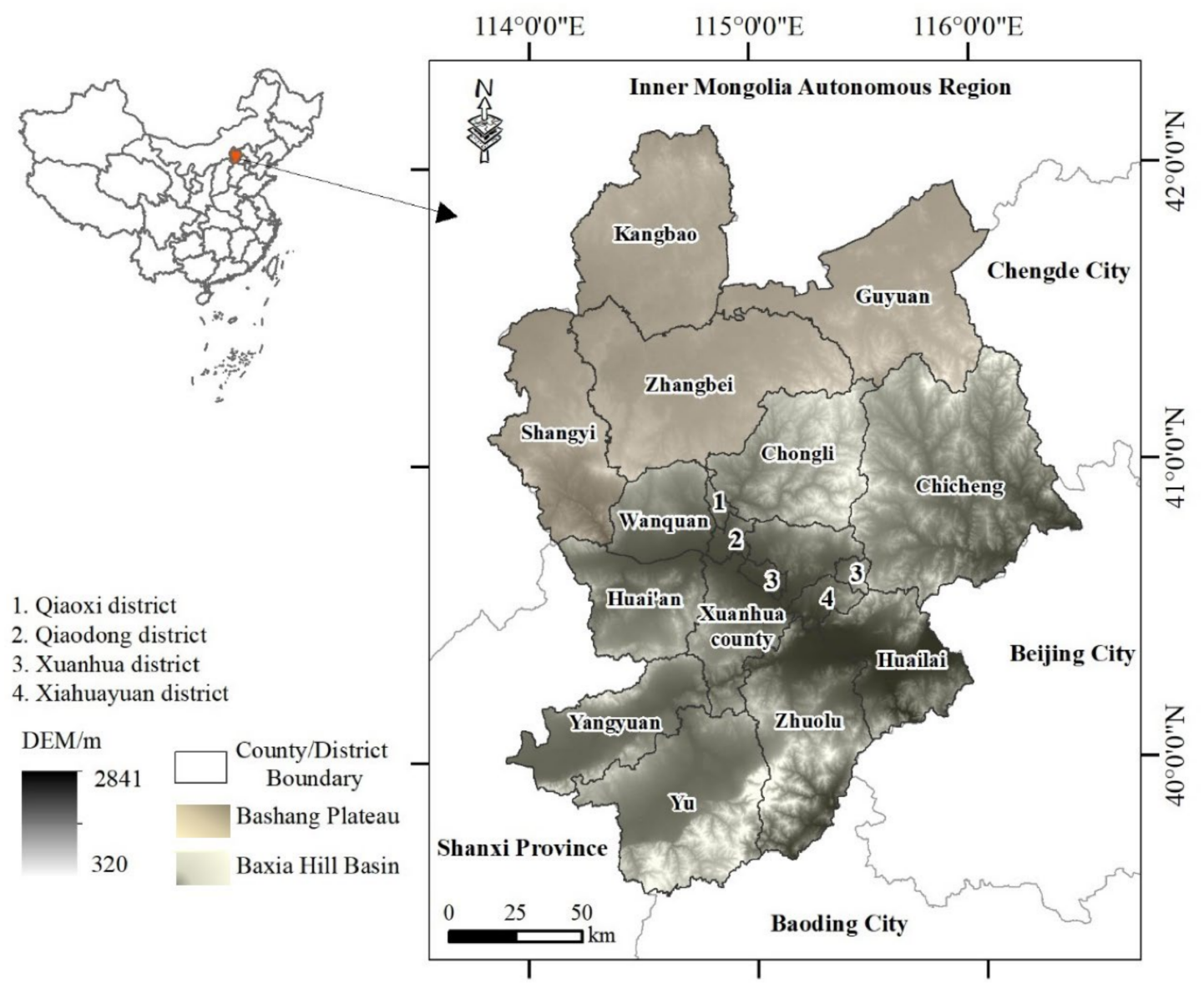

Figure 2. Geographical location of Zhangjiakou City.

\subsection{Methodology}

\subsubsection{Data Collection and Pre-Processing}

This research collected land use, geographic, and socioeconomic data. Land use data were interpreted by remote sensing imagery, including Landsat-Thematic Mapper ${ }^{\mathrm{TM}}$ imagery (1990 and 2000) and Operational Land Imager (OLI) imagery (2015). Land use types contained farmland, orchard, forestland, grassland, urban-rural construction land, transportation land, water areas, and unused land [33]. Geographic data, including spatially interpolated monthly meteorological data by thin-plate spline algorithm, linear approach processed normalized difference vegetation index (NDVI). In terms of solar radiation data, temperature, rain and sunshine were interpolated using the Kriging method in ArcGIS 10.4. Socioeconomic data are as follows. The population were obtained from Hebei Population Census (1991 and 2000) and Hebei Rural Statistical Yearbook (2016). Industry outputs were collected from the Zhangjiakou Economic Yearbook (1990, 2001, and 2016). The price of wheat was collected from the China Statistical Yearbook (1991) and the China Yearbook of Agricultural Price Survey (2004 and 2016). Reservoir capacity cost data were obtained from the China Water Statistical Yearbook (1991, 2001, and 2016). The price of chemical fertilizer was from the China Agricultural Information Network. http:/ / www.agri.cn (accessed on 24 December 2021)

The grid method is an efficient pathway to achieve the spatial fusion of multi-source data and models [34]. Therefore, the overall study area was meshed by grids $(1 \mathrm{~km} \times 1 \mathrm{~km}$ each) to measure the values of different data layers. 


\subsubsection{Methods for Valuation of LUFs}

LUFs' Classification and Indicator Systems

It is preferred to classify LUFs in terms of the economic, social, and ecological dimensions of sustainability [4,27]. Located in the Beijing-Tianjin poverty belt, Zhangjiakou City needs to improve its economic benefits. In addition, the city is the main agricultural product supply base and ecological environment support area for the Beijing-Tianjin-Hebei region. Therefore, LUFs can be categorized into economic function, social function, and ecological function from the perspectives of land use and ecological, livelihood, and economic conditions in Zhangjiakou. Regarding land use economic function, we chose two factors reflecting agricultural and non-agricultural production to value land use agriculture and secondary and tertiary industrial activities. For the social function, food supply and residence support were used to measure the land use value that secures food security and balanced space loading. The ecological function was calculated using soil conservation and gas regulation, indicating the value of soil and water conservation and clean air services. The LUFs' economic value was measured as follows:

(a) Agricultural production indicator

The value of agricultural production refers to agricultural production activities' economic value. It is represented by the total value of production from agriculture, forestry, livestock, and fisheries, which is closely tied to farmland, orchards, forests, grasslands, and water areas [35]. It should be noted that economic forests such as caragana, sea buckthorn, and Chinese wolfberry, and grassland for grazing and livestock breeding, are distributed mainly in areas with a slope of less than $20^{\circ}$, according to the field sampling and household survey. The calculation method is as follows:

$$
G P_{i}=\sum \frac{A V O_{j k}}{A R G L_{j p}} \times A R G L_{i p}
$$

where $G P_{i}$ is the value of agriculture production in grid $i, A V O_{j k}$ ( $k$ represents agriculture, forestry, livestock, and fishery, respectively) is the agriculture value in town $j, A R G L_{i p}$ and $A R G L_{j p}$ ( $p$ represents farmland, forestland, grassland, and water, respectively) are the area of land use types in grid $i$ and town $j$, respectively.

(b) Non-agricultural production indicator

The value of non-agricultural production is the economic value generated by the industrial and service sectors, characterized by the output value of secondary and tertiary industries. The area and intensity of the nighttime light can reflect the economic distribution of the region and its internal differences [36,37]. The mining industry and the agricultural byproducts processing industry are also distributed in towns and rural areas. However, these economic activities often occur during the daytime, and it is difficult for the nighttime light data to reflect this phenomenon. Thus, we combined the data for urban-rural construction land, traffic land, and nighttime light to model the economic value of non-agricultural production. The calculation method is as follows:

$$
N A P_{i}=\sum \frac{G 23_{j}}{S_{j}} \times S_{i} \times\left(1+I_{i}\right)
$$

where $N A P_{i}$ is the value of non-agricultural production in grid $i, G 23_{j}$ is the total output of the secondary and tertiary industries in county $j, S_{i}$ and $S_{j}$ are the total areas of nighttime light value over 0 within the urban-rural construction land in grid $i$ and county $j$, respectively, and $I_{i}$ is the nighttime light density in grid $i$.

(c) Food supply indicator

The food supply value represents people's willingness to pay for the food provided by farmland [38]. The standard grain yield is introduced to make the grain production capacity comparable in different regions. First, we estimate the standard grain (winter wheat) production from wheat, corn, millet, naked oats, and potatoes according to the yield ratio coefficients [39]. Second, we establish a predictive model for the standard grain by 
NDVI and farmland. Third, the market price method is applied to assess the value of the food supply. The calculation method is as follows:

$$
\begin{gathered}
V G_{i}=G Y_{i} \times P G \\
G Y_{i}=a N D V_{i}+b A R E_{i}
\end{gathered}
$$

where $V G_{i}$ and $G Y_{i}$ indicate the food supply value and the standard grain production in grid $i$, respectively, $P G$ refers to the market price of wheat, $N D V_{i}$ and $A R E_{i}$ are the NDVI values and the farmland areas in grid $i$, separately. $a$ and $b$ are the regression coefficients for $N D V_{i}$ and $A R E_{i}$, respectively, which are determined by a linear regression for the standard grain production, the NDVI value, and the farmland area.

(d) Residence support indicator

Residence support means the land resources providing homes for the population [15]. Its value is generally the monetary value that people pay for their residential space. As is well known, construction land is the primary base for residency. The nighttime light shows a significant correlation with the settlements [40]. The calculation method is as follows:

$$
\begin{gathered}
V P_{i}=P O P D_{i} \times R A R E \times C H S \\
P O P D_{i}=\frac{P O P_{j}}{U R L_{j}} \times U R L_{i} \times\left(1+\frac{U R N L_{i}}{N L_{j}}\right)
\end{gathered}
$$

where $V P_{i}$ is the value of residence support in grid $i, R A R E$ is the per capita living space, CHS is the per area commercial house price, $P O P D_{i}$ is the population density in grid $i$, $P O P_{j}$ is the total population in town $j, U R L_{j}$ and $U R L_{i}$ are the area of the urban-rural construction land in town $j$ and grid $i$, respectively. $N L_{j}$ and $U R N L_{i}$ are the total nighttime light densities of the urban-rural construction land in town $j$ and grid $i$, respectively.

(e) Gas regulation indicator

Gas regulation indicates the ability of land use controlling greenhouse gases and purifying the air by fixing $\mathrm{CO}_{2}$ and releasing $\mathrm{O}_{2}$. As Liu et al. [41] described, the CarnegieAmes-Stanford approach (CASA) is used to estimate the net primary productivity (NPP) of land use/cover. Then, according to the photosynthesis equation, NPP can be converted into a carbon sink [42]. Finally, the value of gas regulation is estimated using the alternative cost method, namely, the afforestation cost method and the industrial oxygen production method. The method of calculation is as follows:

$$
\begin{gathered}
V G R_{i}=V C O \times C O_{i}+V O \times O_{i} \\
N P P_{i}=A P A R_{i} \times \varepsilon_{i}
\end{gathered}
$$

where $V G R_{i}$ is the value of gas regulation for grid $i, V C O$ and $V O$ are the cost of $\mathrm{CO}_{2}$ afforestation, and $\mathrm{O}_{2}$ afforestation and industrial oxygen production, respectively. For grid $i, \mathrm{CO}_{i}$ and $\mathrm{O}_{i}$ are the amount of $\mathrm{CO}_{2}$ sequestration $\left(1.63 N P P_{i}\right)$ and $\mathrm{O}_{2}$ release (1.2NPP $P_{i}$, respectively, $N P P_{i}, A P A R_{i}$ and $\varepsilon_{i}$ are the net primary productivity, the amount of photosynthesis radiation, and the efficiency of solar energy utilization, respectively. In order to maintain the continuity and comparability with existing research results and address the huge difficulties in collecting data, this paper adopted the research results of Liu et al. (2013) [41] and Huang et al. (2019) [43] to obtain the cost of $\mathrm{CO}_{2}$ afforestation used in this study was $260.90 \mathrm{RMB} / \mathrm{t}$, while the cost of $\mathrm{O}_{2}$ afforestation and industrial $\mathrm{O}_{2}$ production industrial were $352.93 \mathrm{RMB} / \mathrm{t}$ and $400 \mathrm{RMB} / \mathrm{t}$, respectively.

(f) Soil conservation indicator

Soil conservation includes the protection of soil fertility, the reduction in soil disuse, and the decrease in soil deposition. Thus, the economic value of soil conservation can be replaced using the sum of the following: the costs of soil fertility conservation, the value of the losses resulting from abandoned land, and the cost of the reduction in sediment accumulation [44]. We first used RUSLE to simulate the physical quantity of the soil conser- 
vation [45], and then the market value, the opportunity, and the alternative engineering methods are applied to calculate its economic value [43]. The method of calculation is as follows:

$$
\begin{gathered}
V S R_{i}=V a_{i}+V b_{i}+V c_{i} \\
V a_{i}=A c_{i} \times \sum_{j} C_{j} \times T_{j} \times P_{j} \\
V b_{i}=A c_{i} \times B /(p \times h \times 10000) \\
V c_{i}=\left(A c_{i} / p\right) \times 24 \% \times C c \\
A c_{i}=R_{i} \times K_{i} \times L_{i} \times S_{i} \times\left(1-C_{i} \times P_{i}\right)
\end{gathered}
$$

where $V S R_{i}, V a_{i}, V b_{i}$, and $V c_{i}$ indicate the value of the soil conservation, the soil fertility maintenance, the land abandonment reduction, and the sediment deposition alleviation for grid $i$, respectively. $A c_{i}$ is the amount of soil conservation for grid $i, C_{j}$ is the pure content of nitrogen $(0.136 \%)$, phosphorus $(0.053 \%)$, and potassium $(1.92 \%)$ in the soil, which are obtained from Book of Soils of Hebei Province; $T_{j}$ is the coefficient of pure amount of nitrogen (5.882), phosphorus (3.373), and potassium (1.667) to the fertilizer conversion [46], and $P_{j}$ is the fertilizer price [45]. $B, p, h$, and $C c$ represent the forestry annual income (i.e., annual gross output of forestry if the land is not abandoned), the density of soil bulk, the thickness of surface soil, and the reservoir capacity cost (i.e., the cost of reservoir dredging following siltation caused by soil erosion) obtained from Li and Ren's results [47], respectively. For grid $i, R_{i}, K_{i}, L_{i}, S_{i}, C_{i}$ and $P_{i}$ indicate the factors of rainfall erosivity, soil erodibility, slope length, steepness, cover management, and support practice, separately [46].

\section{LUFs' Value Calculation}

The GDP deflator index is an important indicator that comprehensively and truly measures price changes and reflects inflation, which has been used in eliminating the impact of inflation and other factors on prices [48]. The GDP deflator index is the ratio of GDP at current prices to GDP at comparable prices for a given period. Therefore, to capture the real value of LUFs in different years and to make them comparable, we use the GDP deflator index to turn the prices involved in the calculation of functional indicators in 1990, 2000, and 2015 into prices at constant 1990 prices.

The FUNV index (defined below) is developed to calculate the individual function by introducing the comprehensive evaluation method. In this model, the value of each land use function is calculated from the values of multiple indicators. The calculation method is as follows:

$$
F U N V_{i}=\sum_{j=1}^{n} I N D_{i j} W_{i j}
$$

where $F U N V_{i}$ refers to the value of $L U F_{i}, I N D_{i j}$ captures the value of indicator $j$ in $L U F_{i}$, and $W_{i j}(0.5)$ represents the weight of indicator $j$ in $L U F_{i}$.

\subsubsection{Identifying the Diversity and Dominance of LUFs}

The diversity of LUFs is the status of LUFs simultaneously reflecting economic, social, and ecological functions [14,32] and is usually characterized by the different types of combinations of LUFs. If the function's value is higher than that of other functions, it can be called the dominant function. The values of economic, social, and ecological LUFs in the same grid were compared using spatial superposition analysis. Then the multifunctionality and the dominant function of the grid were determined (Table 1). 
Table 1. Discriminant basis for diversity and dominance types of LUFs.

\begin{tabular}{ccc}
\hline Dominance Type of LUFs & Diversity Type of LUFs & Criterion \\
\hline \multirow{4}{*}{ ENFD } & ENP-SS-ELT & ENV $>$ SV $>$ ELV \\
& EP-SS & ENV $>$ SV, and ELV $=0$ \\
& ENP-ELS-ST & ENV $>$ ELV $>$ SV \\
& ENP-ELS & ENV $>$ ELV, and SV $=0$ \\
& ENI & ENV $\neq 0$, ELV $=0$, and SV $=0$ \\
\hline SP-ENS-ELT & SV $>$ ENV $>$ ELV \\
& SP-ENS & SV $>$ ENV, and ELV $=0$ \\
& SP-ELS-ENT & SV $>$ ELV $>$ ENV \\
& SP-ELS & SV $>$ ELV, and ENV $=0$ \\
& SI & SV $\neq 0$, ELV $=0$, and ENV $=0$ \\
\hline \multirow{2}{*}{ ELFD } & ELV $>$ ENV $>$ SV \\
& ELP-ENS-ST & ELV $>$ ENV, and SV $=0$ \\
& ELP-ENS & ELV $>$ SV $>$ ENV \\
& ELP-SS-ENT & ENV $>$ SV, and ENV $=0$ \\
& ELI & ELV $\neq 0$, SV $=0$, and ENV $=0$
\end{tabular}

Notes: ENFD: economic function is dominant; SFD: social function is dominant; ELFD: ecological function is dominant; ENP: economic function is primary; SP: social function is primary; ELP: ecological function is primary; ENS: economic function is secondary; SS: social function is secondary; ELS: ecological function is secondary; ENT: economic function is tertiary; ST: social function is tertiary; ELT: ecological function is tertiary; ENI: economic function is individual; SI: social function is individual; ELI: ecological function is individual; ENV: economic function value; SV: social function value; and ELV: ecological function value.

\section{Results}

4.1. Evolution Characteristics of LUFs

4.1.1. Change in the Total Value of LUFs

Between 1990 and 2015, the values of the economic, social, and ecological LUFs in Zhangjiakou improved by annual averages of $76.28 \%, 84.32 \%$, and $1.11 \%$, respectively. In 2015 , the values of these three functions were RMB $486.51 \times 10^{8}$, RMB $2886.20 \times 10^{8}$, and RMB $184.95 \times 10^{8}$, respectively (Table 2 ).

Table 2. Variation in the value of LUFs in the whole case study area of Zhangiiakou City (1990-2015).

\begin{tabular}{cccccccccc}
\hline \multirow{2}{*}{$\begin{array}{c}\text { Function } \\
\text { Type }\end{array}$} & \multicolumn{2}{c}{ Function Value/10 $\mathbf{8}^{\mathbf{8}} \mathbf{R M B}$} & \multicolumn{3}{c}{ Net Change in Function Value/10 } & RMB & \multicolumn{3}{c}{$\begin{array}{c}\text { Annual Average Variation Ratio of } \\
\text { Function Value/\% }\end{array}$} \\
\cline { 2 - 12 } & $\mathbf{1 9 9 0}$ & $\mathbf{2 0 0 0}$ & $\mathbf{2 0 1 5}$ & $\mathbf{1 9 9 0 - 2 0 0 0}$ & $\mathbf{2 0 0 0 - 2 0 1 5}$ & $\mathbf{1 9 9 0 - 2 0 1 5}$ & $\mathbf{1 9 9 0 - 2 0 0 0}$ & $\mathbf{2 0 0 0 - 2 0 1 5}$ & $\mathbf{1 9 9 0 - 2 0 1 5}$ \\
\hline Economic & 24.24 & 69.58 & 486.51 & 45.34 & 416.93 & 462.27 & 18.70 & 39.95 & 76.28 \\
Social & 130.71 & 349.26 & 2886.2 & 218.55 & 2536.94 & 2755.49 & 16.72 & 48.43 & 84.32 \\
Ecological & 144.8 & 157.55 & 184.95 & 12.75 & 27.4 & 40.15 & 0.88 & 1.16 & 1.11 \\
\hline
\end{tabular}

\subsubsection{Changes of the Spatial Patterns of LUFs}

As shown in Table 3, the three individual functions' high/low values were significantly clustered in space to form hot spots, which were implied by Moran's I's significantly positive values. In addition, the change ranges of $G(d)$ values of these three individual functions were small, reflecting the fact that their spatial patterns were basically consistent in the period 1990-2015.

As illustrated in Figure 3, the high values of the economic function were distributed mainly in the central counties, such as Xuanhua county, Xuanhua district, Huailai county, and Qiaodong district, because the proportions of secondary and tertiary industries were higher in these counties. Therefore, these counties were the "hotspot" regions for the economic function in Zhangjiakou City. Between 1990 and 2015, the values of the economic function increased in the whole of the city. Qiaodong district became the area with the most significant increase. The center of gravity moved northward from Xuanhua district to Xuanhua county, related to the adjustment in the local industrial structure. 
Table 3. Moran's I and G(d) of LUFs in the whole case study area of Zhangjiakou City (1990-2015).

\begin{tabular}{|c|c|c|c|c|}
\hline \multicolumn{2}{|c|}{ Index } & Economic Function & Social Function & Ecological Function \\
\hline \multirow{3}{*}{ Moran's I } & 1990 & $0.808^{* * *}$ & $0.589 * * *$ & $0.934^{* * *}$ \\
\hline & 2000 & $0.917^{* * *}$ & $0.630 * * *$ & $0.931^{* * *}$ \\
\hline & 2015 & $0.814^{* * *}$ & $0.705^{* * *}$ & $0.926^{* * *}$ \\
\hline \multirow{3}{*}{$\mathrm{G}(\mathrm{d})$} & 1990 & $0.001^{* * *}$ & $0.001^{* * *}$ & $0.000^{* * *}$ \\
\hline & 2000 & $0.002^{* * *}$ & $0.001^{* * *}$ & $0.000 * * *$ \\
\hline & 2015 & $0.002^{* * *}$ & $0.001^{* * *}$ & 0.000 *** \\
\hline
\end{tabular}

Note: ${ }^{* * *}$ indicates significant at the 0.01 level.
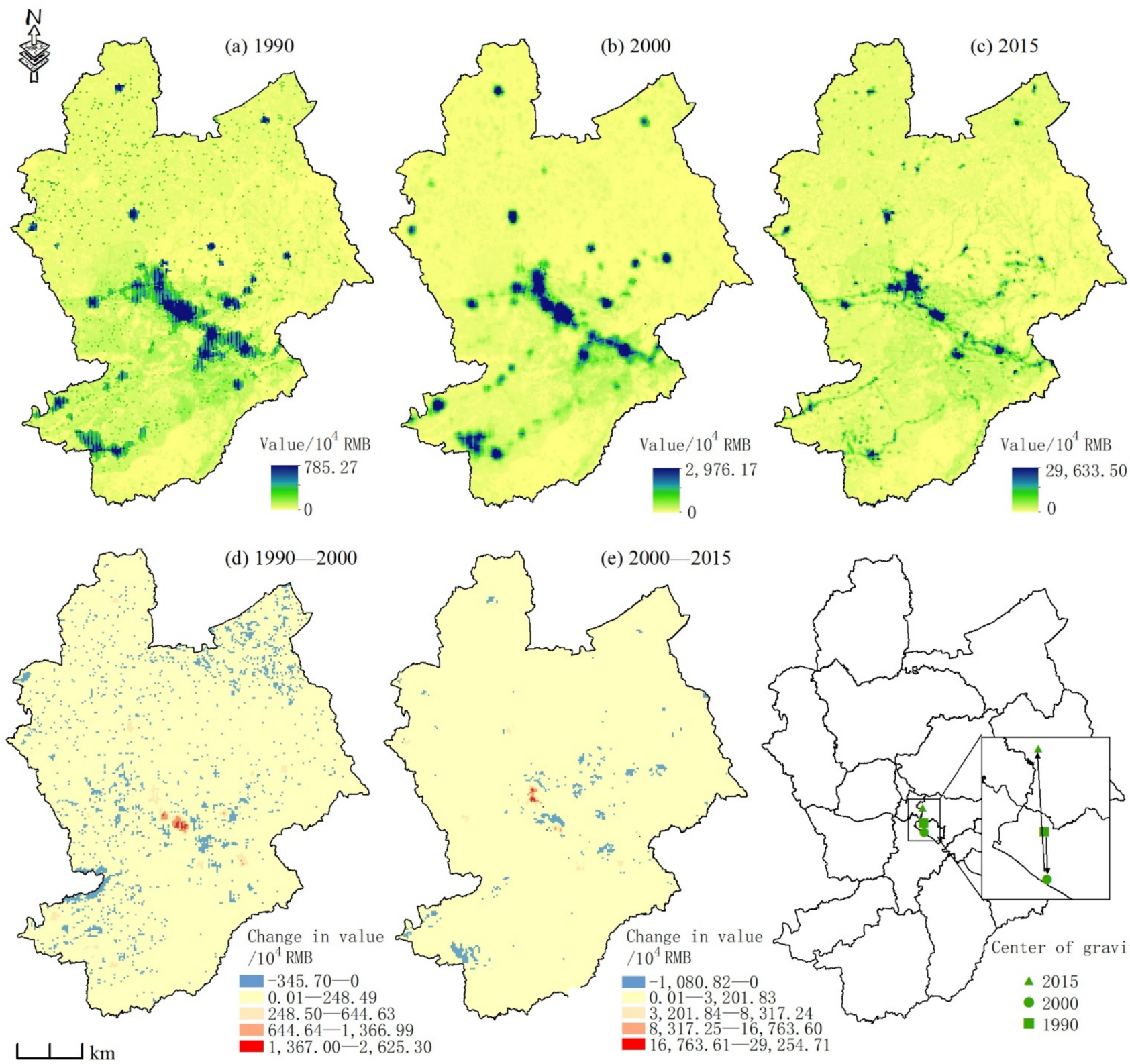

(e) $2000-2015$
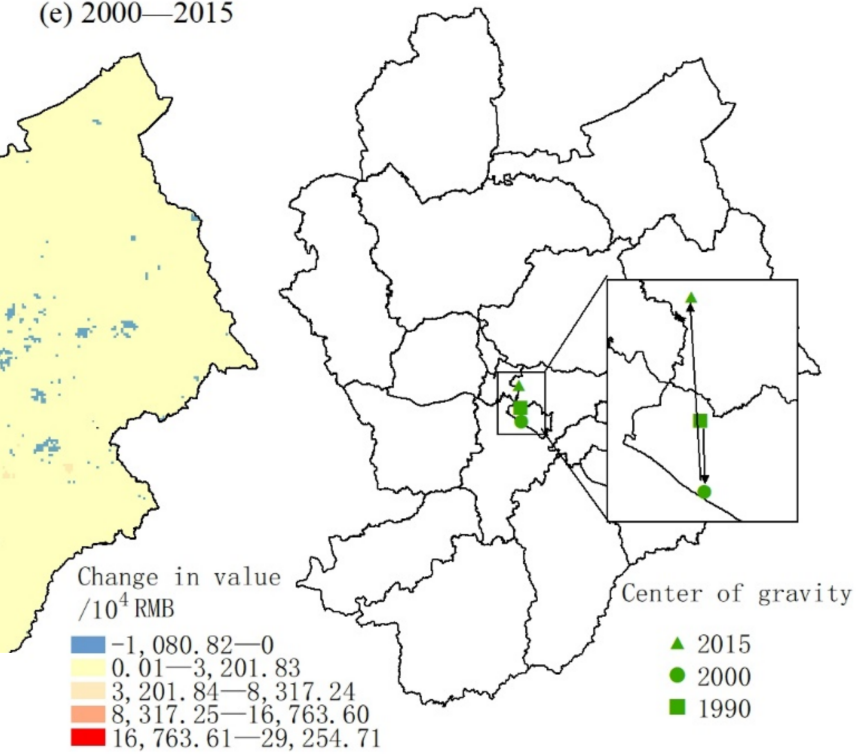

Figure 3. Spatial evolution of land use economic function at grid scale in Zhangjiakou City in 1990-2015. Notes: Subfigure (a-c) mean the spatial value distribution of land use economic function in 1990, 2000 and 2015, respectively. Subfigure (d,e) mean the spatial value change of land use economic function in 1990-2000 and 2000-2015, respectively.

For the social function, the high-value areas were concentrated in Qiaoxi, Qiaodong, and Xuanhua districts. In contrast, the low-value areas were distributed mainly in Chongli, Chicheng, and Yu counties, where there are mountains with poor natural backgrounds for 
agricultural production and poor infrastructure (Figure 4). In 1990-2000, the proportion of regions with a decreased value of the social function $(45.78 \%)$ was slightly higher than that of regions with an increased value (43.28\%). It might be related to the decrease in food production caused by drought. However, in 2000-2015, improved social function values were dominant, especially in Qiaodong and Xuanhua districts. In 1990-2015, the center of gravity of the social function within Qiaodong district moved first to the southwest and then to the southeast, related to the rapid population growth in the city's southern counties in recent years.

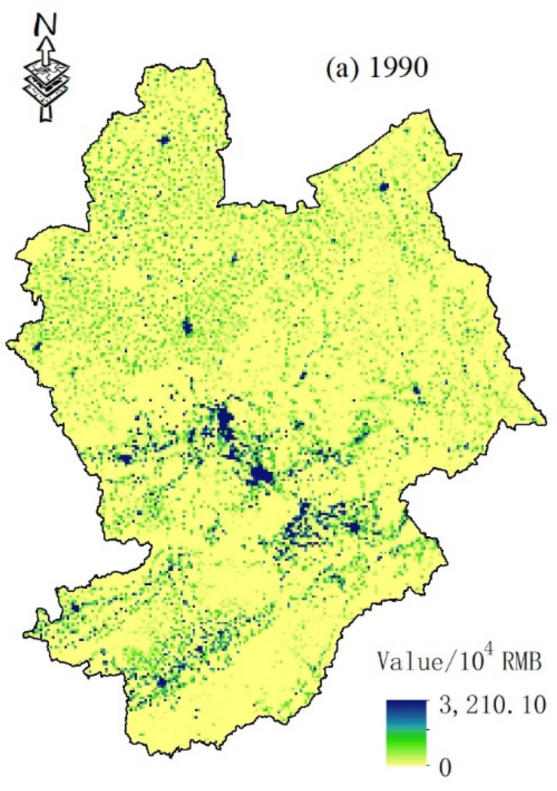

(d) $1990-2000$

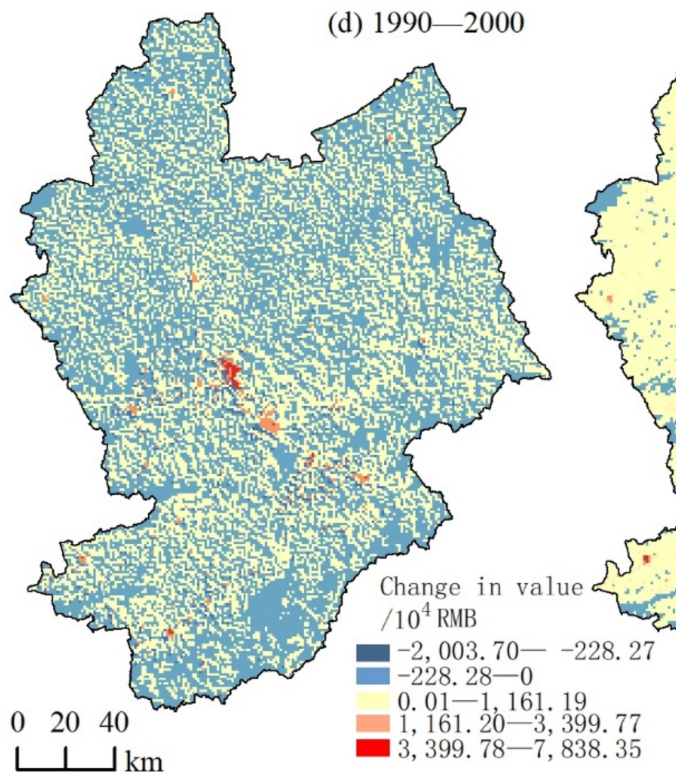

(b) 2000

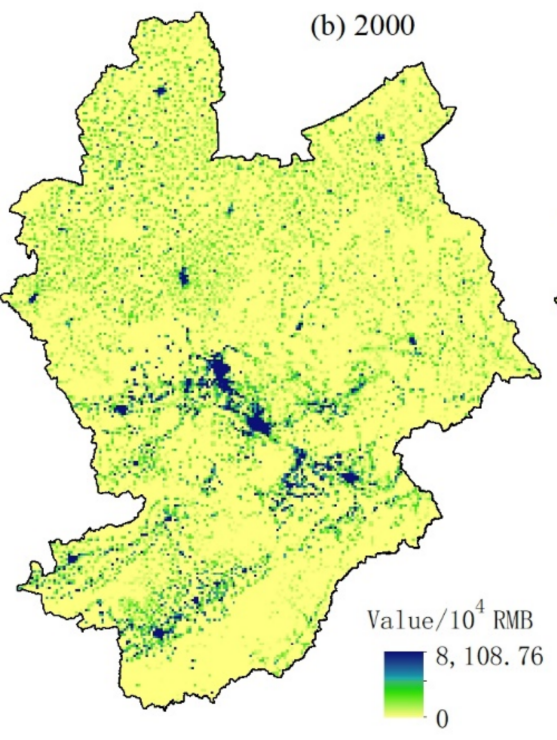

(e) $2000-2015$
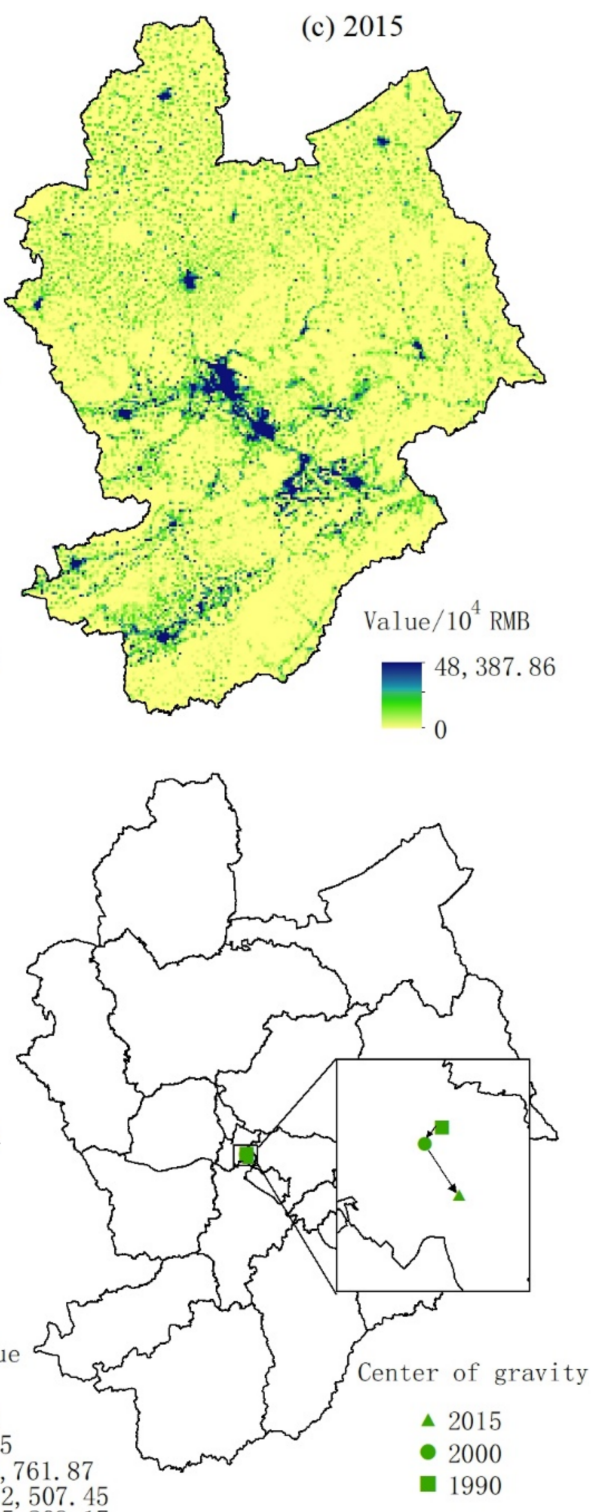

Figure 4. Spatial evolution of land use social function at grid scale in Zhangiiakou City in 1990-2015. Notes: Subfigure $(\mathbf{a}-\mathbf{c})$ mean the spatial value distribution of land use social function in 1990, 2000 and 2015, respectively. Subfigure (d,e) mean the spatial value change of land use social function in 1990-2000 and 2000-2015, respectively.

In the period 1990-2015, the value of the ecological function was high in the east and low in the west (Figure 5) because of the more forests and grasslands in the eastern mountains and the greater vegetation capacity there to sequester carbon and release oxygen $[6,14]$. In addition, the low-value areas were primarily located in the central Yanghe Valley, which 
was related to the greater area of construction land and the lesser area of vegetation cover in the region. Between 1990 and 2015, the percentage of areas with an increased value of the ecological function went up from $65.73 \%$ to $83.50 \%$. Meanwhile, the center of gravity in Xuanhua county shifted first to the northwest and then to the southwest. The reason was that the city was greening barren hills, constructing nature reserves, and restoring vegetation around scenic and mining areas. It is noteworthy that the decrease in ecological function values in the period 1990-2000 occurred throughout the city, related to the decline in annual precipitation in 2000.
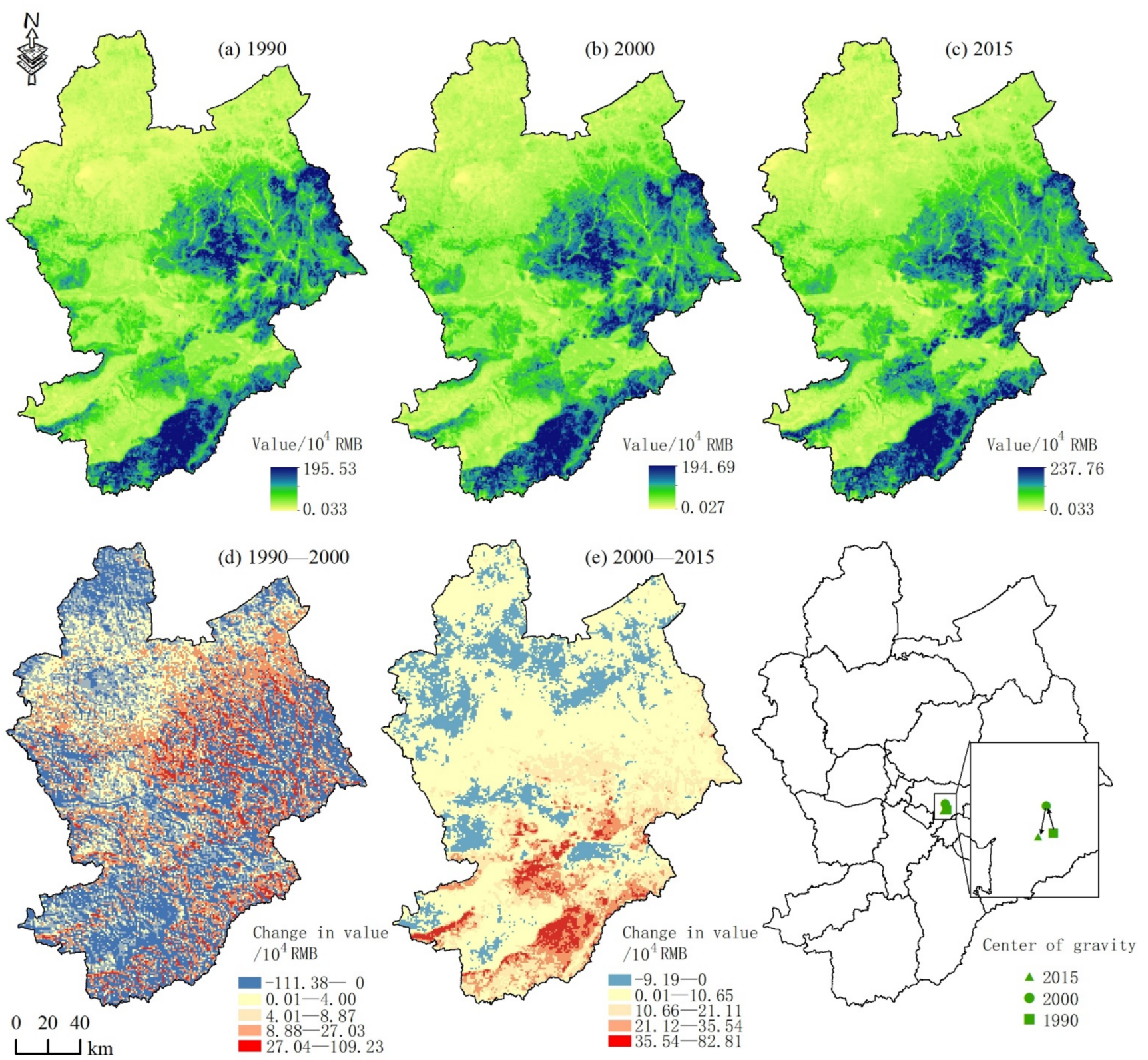

Figure 5. Spatial evolution of land use ecological function at grid scale in Zhangjiakou City in 19902015. Notes: Subfigure (a-c) mean the spatial value distribution of land use ecological function in 1990, 2000 and 2015, respectively. Subfigure (d,e) mean the spatial value change of land use ecological function in 1990-2000 and 2000-2015, respectively.

\subsection{Evolution in Diversity and Dominance of LUFs}

\subsubsection{Change in Diversity of LUFs}

The combination types of three LUFs existed in about $99 \%$ of Zhangjiakou City and the diversity of LUFs increased from seven to nine in 1990-2015 (Figure 6). Of these, between 
1990 and 2000, the functional combination area of ELP-ENS-ST took the largest part of the city's total area, with 50.50\%. The second-ranked combination type changed from ELPSS-ENT (accounting for 23.69\%) to SP-ELS-ENT (20.52\%). The functional combination area of SP-ELS accounted for the smallest proportion, with $60.35 \%$. Between 2000 and 2015, the functional combination area of SP-ENS-ELT maintained an absolute advantage, accounting for $33.37 \%$ of the city's area, while ELI accounted for the smallest proportion, with $0.01 \%$.
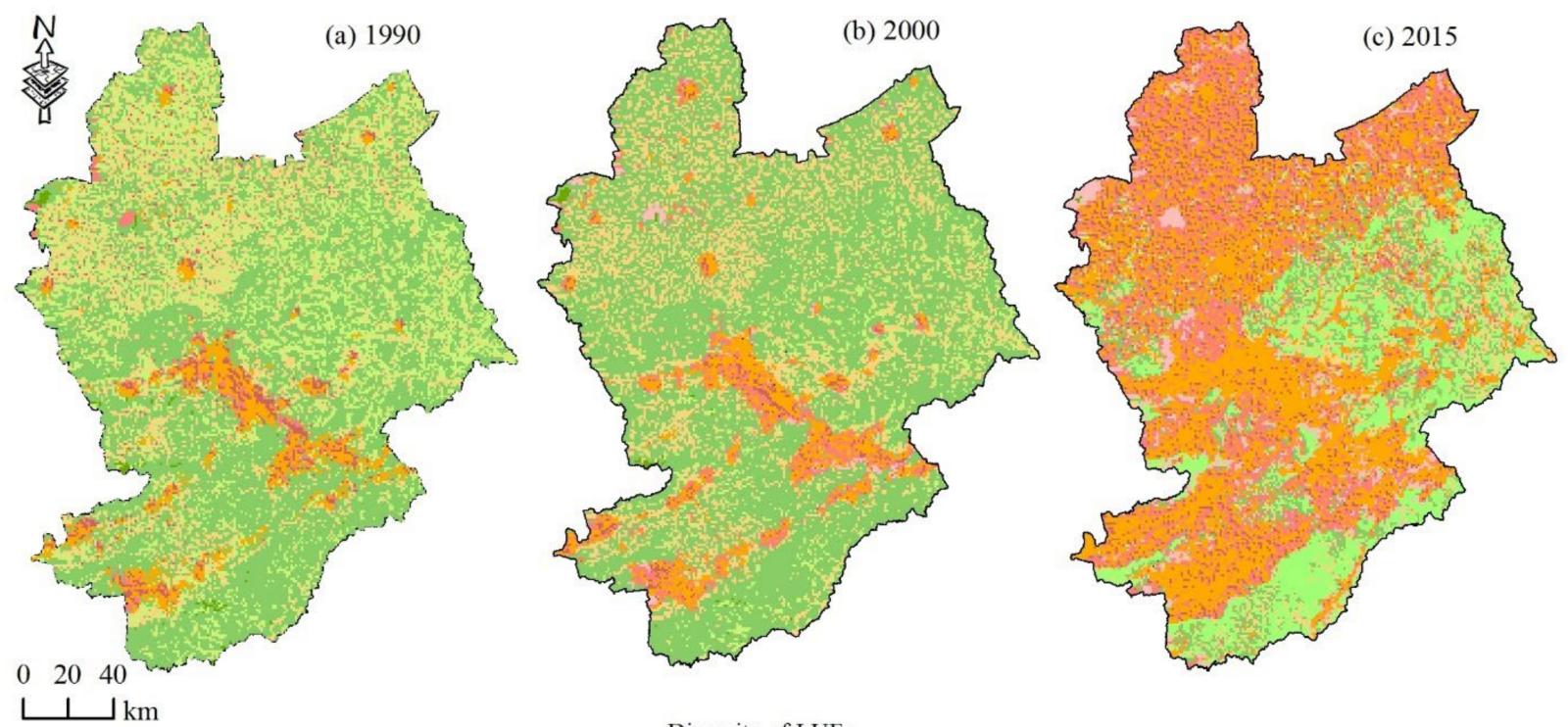

Diversity of LUFs

ELP-ENS ELP-ENS-ST ELP-SS-ENT $\square$ ELI SP-ELS $\square$ SP-ELS-ENT $\square$ SP-ENS-ELT ENP-ELS $\square$ ENP-ELS-ST $\square$ ENP-SS-ELT

Figure 6. Spatial evolution of the diversity of LUFs at grid scale in Zhangjiakou City in 1990-2015. Notes: LUFs means land use functions; ELP-ENS means the combination of two functions where ecological function is primary and economic function is secondary; ELP-ENS-ST means the combination of three functions where ecological function is primary, economic function is secondary, and social function is tertiary; ELP-SS-ENT means the combination of three functions where ecological function is primary, social function is secondary, and economic function is tertiary; ELI means ecological function is individual; SP-ELS means the combination of two functions where social function is primary and ecological function is secondary; SP-ELS-ENT means the combination of three functions where social function is primary, ecological function is secondary, and economic function is tertiary; SP-ENS-ELT means the combination of three functions where social function is primary, economic function is secondary, and ecological function is tertiary; ENP-ELS means the combination of two functions where economic function is primary and ecological function is secondary; ENP-ELS-ST means the combination of three functions where economic function is primary, ecological function is secondary, and social function is tertiary; and ENP-SS-ELT means the combination of three functions where economic function is primary, social function is secondary, and ecological function is tertiary. Subfigure (a-c) mean the diversity of LUFs in 1990, 2000 and 2015, respectively.

\subsubsection{Change in Dominance of LUFs}

Between 1990-2015, there were shifts in the dominance of LUFs with regards to the economic, social, and ecological functions (Figure 7). The percentage of dominant functional area to total citywide area, the dominant function was ELFD $(74.53 \%)>$ SFD $(21.45 \%)>\operatorname{ENFD}(4.02 \%)$ in 1990; ELFD (67.42\%) > SFD (26.56\%) > ENFD (6.03\%) in 2000; and SFD $(40.76 \%)>\operatorname{ENFD}(33.32 \%)>\operatorname{ELFD}(25.92 \%)$ in 2015. Concerning the percentage of dominant function conversion area to total conversion area, the change from ELFD to SFD was most significant $(46.68 \%$ ) in 1990-2000, while the change from ELFD to ENFD was most significant (67.18\%) in 2000-2015, occurring mostly in Zhangbei, Chicheng, and Kangbao counties. 

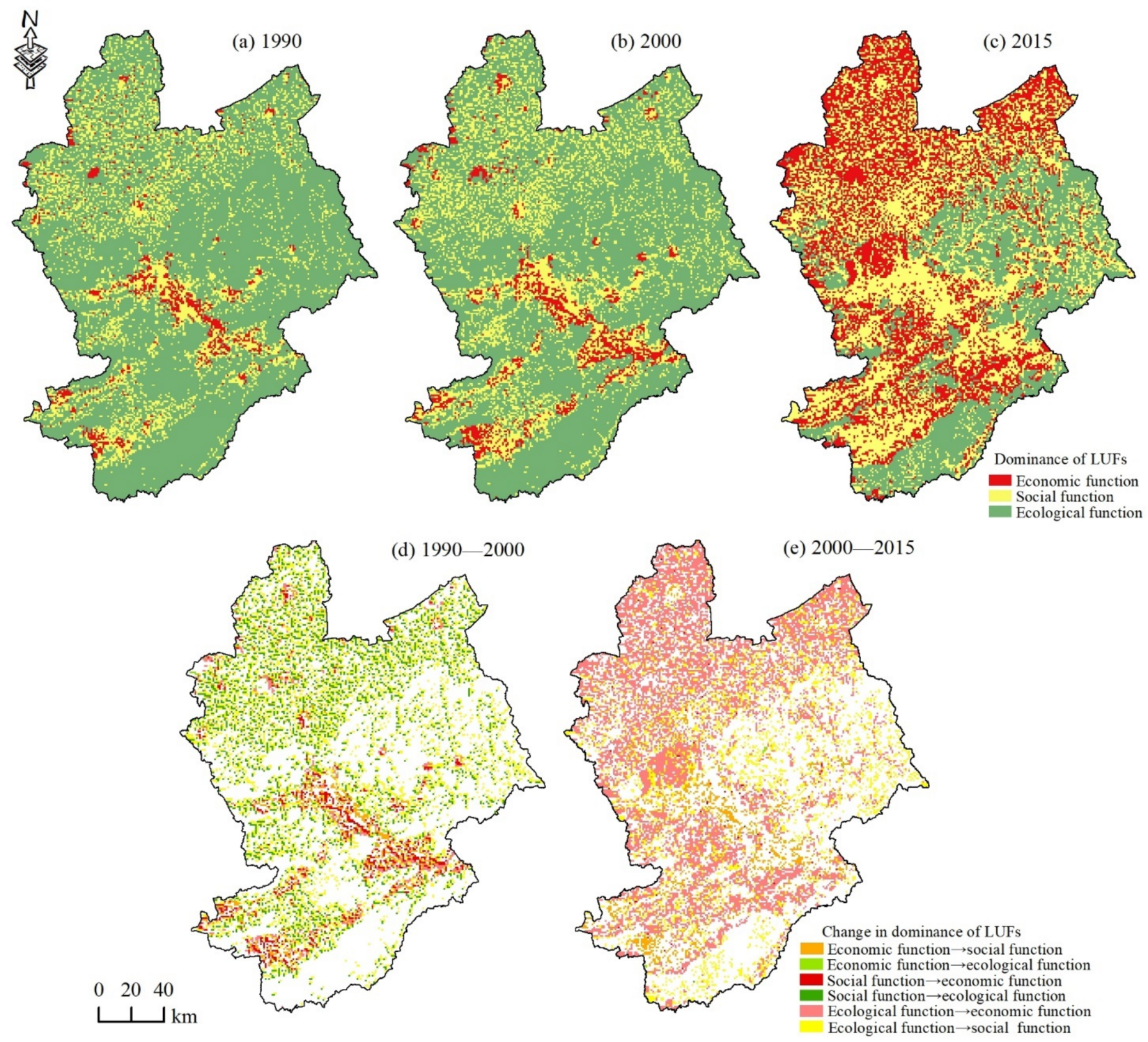

Figure 7. Spatial evolution of dominance of LUFs at grid scale in Zhangjiakou City in 1990-2015. Notes: LUFs means land use functions; $\rightarrow$ means changes into. Subfigure $(\mathbf{a}-\mathbf{c})$ mean the dominance types of LUFs in 1990, 2000 and 2015, respectively. Subfigure (d,e) mean the dominance change of LUFs in 1990-2000 and 2000-2015, respectively.

\section{Discussion}

5.1. Implications for Identification and Optimization of Ecological-Production-Living Space

As Figure 8 shows, under the influence of human values oriented toward protecting the environment, growing the economy, and improving livelihoods, land use system performs ecological, economic, and social functions. LUFs' value reflects visually and quantitatively the benefits that the land use system provides for humanity. This paper measures the dominance and diversity of LUFs from the perspective of LUFs' value, which can provide an important viewpoint for the identification and the optimization of ecological-production-living space. 


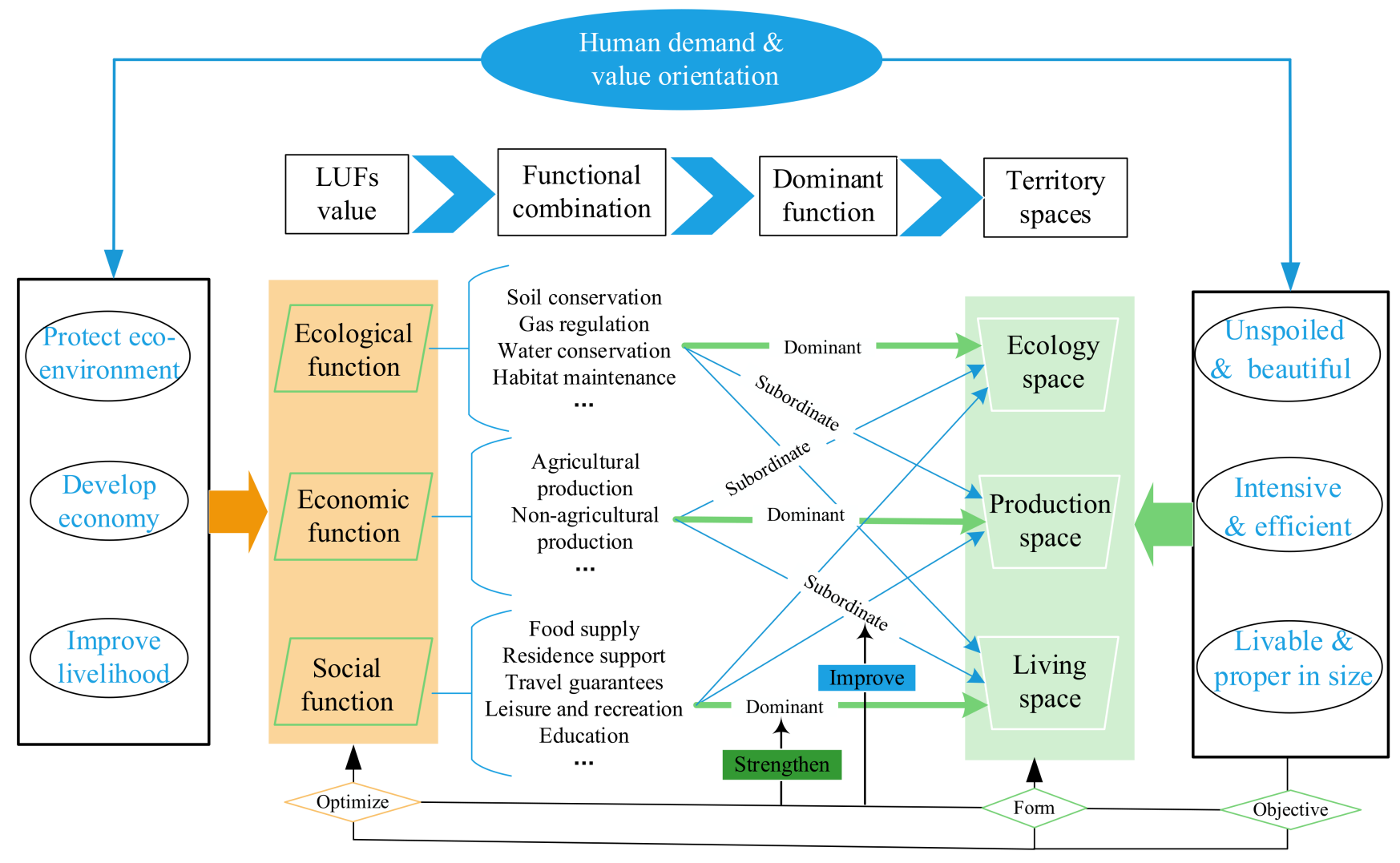

Figure 8. The conceptual framework of optimization of ecological-living-production space based on LUFs' value.

The ecological-production-living space is the dominant functional space [49,50]. However, it failed to identify land use dominant function as prior physical quantity accounting units of LUFs are not directly comparable. In this paper, therefore, the ecologicalproduction-living space can be quantitatively identified by the dominant types of LUFs based on max value among LUFs. Of these, production space carries all the production and business activities and is dominated by economic functions including agricultural production, industrial production, and commercial services. Living space is related to human happiness, and its livability and appropriateness depend on social functions including safe living, convenient transportation, and entertainment functions. The ecology space offers ecological products necessary for human beings and supports production and living space to realize their functions. The ecology space is determined by ecological functions including soil and water conservation, gas regulation, habitat maintenance and other functions.

It should be noted that each space is composed of one or more functions. For example, living space is dominated by social functions such as residence support and travel guarantees to ensure regional socioeconomic development. At the same time, living space also has ecological functions, such as habitat maintenance and gas regulation. The diversity of LUFs, in this paper, implies a comparison of dominance and subsidiarity through functional values. Thus, measuring the diversity of LUFs can judge the state of the functional combinations in ecological-production-living space and further propose optimization suggestions for weaker functions.

To shape the intensive and efficient production space, the livable living space, and the unspoiled ecological space, optimizing production-life-ecology space should restructure the human value orientation towards LUFs, i.e., improving the coherence of LUFs and weaker LUFs. Therefore, production space focuses on enhancing the value of economic functions by promoting agricultural production, non-farm production, and other economic functions to maintain human survival and sustenance. However, it is also essential to halt 
the adverse environmental effects brought about by production activities. The optimization of living space should put people first by highlighting the value of social functions, such as coordinating urban forms with the carrying capacity of different environments and further improving infrastructure services and enriching the entertainment possibilities for residents. With the implementation of the rural revitalization strategy, rural infrastructure should be further improved, and industries with local characteristics should be developed to build a beautiful rural environment in terms of its ecological, industrial, spiritual, and esthetic appeal [51]. Recently, the public has been paying more attention to "quality of life," supported by the living well in the environment and spiritual and esthetic pleasures, and an excellent ecological environment. Therefore, the optimization of ecology space should emphasize the value of the ecological function. We ought to not only build an ecological security pattern that prioritizes ecology, but also restrict productive activities and improve the living conditions for local inhabitants.

\subsection{Coordinated Improvement for LUFs in Zhangjiakou City}

LUFs value in Zhangjiakou City was increasing steadily, while the dominant function was continually changing. As shown in Figure 9, between 1990 and 2000, although the economic and social functions were constantly strengthened, the ecological function still occupied a dominant position in terms of the whole region. This fact was caused by the slower growth of industrialization and urbanization, and the massive construction of ecological projects. Specifically, Zhangjiakou City has formally implemented reform and opening up since 1995 and formed the ecological barrier for Beijing and Tianjin since 1997 [33]. However, since 2000, the social function has begun to lead because of accelerated economic development and industrialization, increasing demand for wealth and suitable living environments [15]. For example, the iron and steel industry has become the largest in Zhangjiakou City, and the urban built-up area has quadrupled.

Consequently, between 1990-2015, the area dominated by the ecological function has decreased, while the area dominated by the social and economic functions has increased. However, this does not mean that the ecological environment deteriorated; rather, it reflected that people's demands for varied food, comfortable housing, and rapid economic development were urgent. It also reflected that Zhangjiakou City is located in a poverty zone and an ecologically fragile area of northern Hebei Province and is facing the combined pressures of economic development and environmental protection [43] and, consequently, more intense LUFs conflicts. Hence, more attention should be paid to improving the ecological and socioeconomic functions simultaneously and related policy strategies should be developed in response to changing circumstances in the future [52].

From the perspective of spatial coordination of multiple functions, we should make full use of the existing dominant functions for local development, maximize spatial benefits by taking up as few resources as possible at the same time, and improve the resource use efficiency. Meanwhile, in the context of promoting sustainable development and ecological civilization, ecological protection should be placed in a prominent position in the optimization of national territory space. Economic-function-dominated areas should give consideration to their production advantages, improve the intensive use of production space, and promote high-quality development. Social-function-dominated areas are more densely populated and should guide the gathering of living space, give full play to the advantages of towns and cities, and improve residential quality, while paying attention to ecological protection and housing policy. The ecological-function-dominated areas should pay attention to ecological protection and strictly prohibit ecological damage caused by development. 


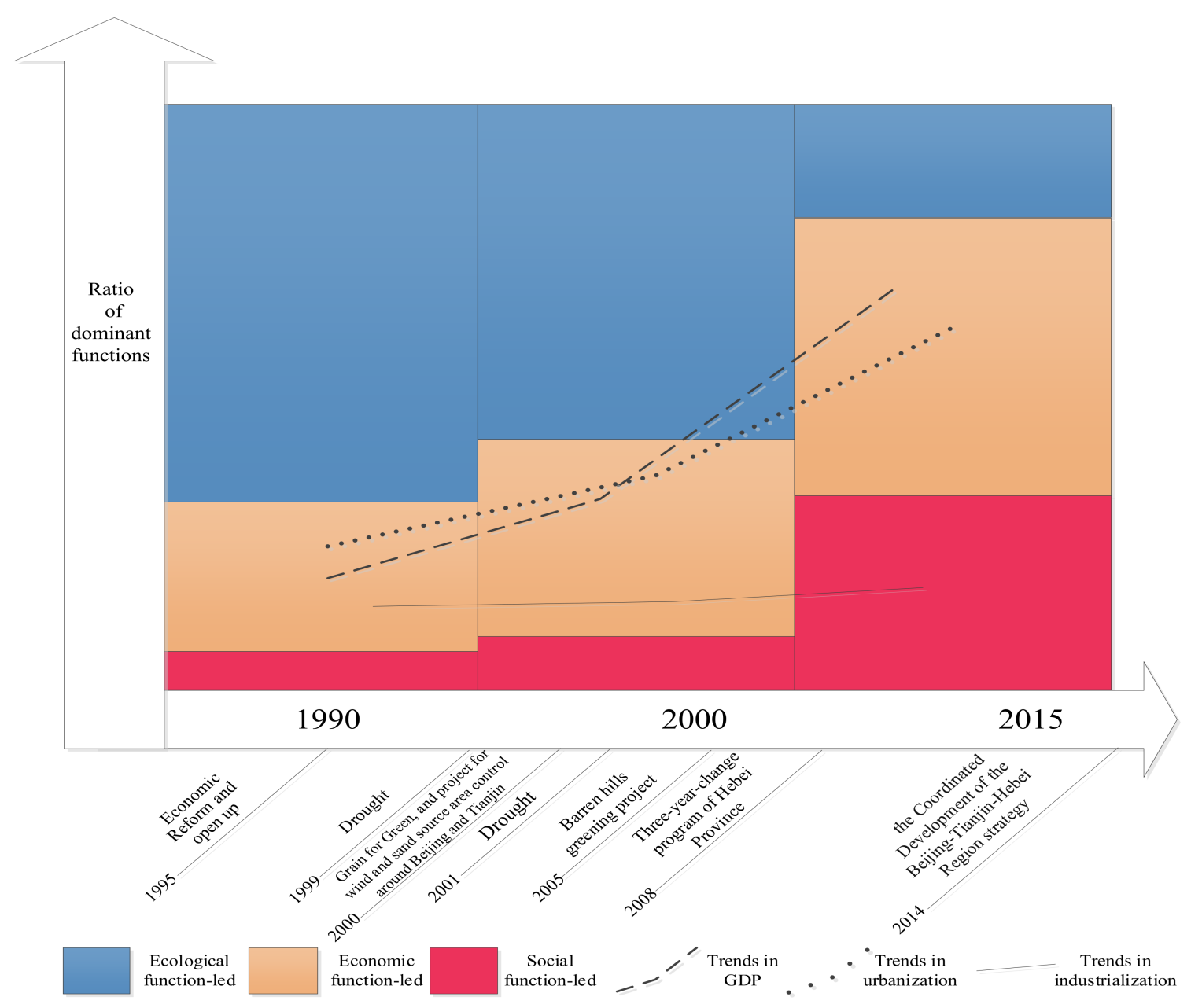

Figure 9. Influencing mechanism for LUFs changes in Zhangjiakou City in 1990-2015.

\subsection{Advantages and Limitations}

LUFs highlight the supply of products with human participation and their value orientation in production process, where production, circulation and consumption follow the law of value. Only by fully understanding the LUFs value from the perspective of "demand-consumption" can we better develop targeted policies to properly utilize land resources, protect the environment, and promote the economy. Thus, in terms of "demand-function-value" perspective, this paper develops a new accounting approach that characterizes LUFs by measuring the monetary value of tangible goods and intangible services. LUFs valuation can draw more attention to reasonable regional land use as people perceive monetary values more clearly. The quantification and integration of LUFs value contributes to solving the problem of the unified measurement units of natural assets, and has the advantage of being additive and reflecting the functional value of land use. Therefore, the approach contributes to comparing the relationship between land exploitation, ecosystem conservation, and socioeconomic development and helps to use economic leverage to achieve the efficient allocation and ecological protection for land resources.

Overall, this study enhanced the knowledge of LUFs value in prefecture-level cities in China and may improve China's regional land policies. However, this paper has several limitations. Firstly, LUFs are challenging to observe directly, as they are the implicit forms of land use [53]. Indeed, it is difficult to exhaust the list of indicators in the accounting of each function. Although we have constructed a set of quantitative models to make the value of LUFs calculable from available data, the values captured only partly mirror the LUFs beneficiaries' needs and may bias market-provided information [54]. In addition, the 
volatility of market prices inevitably leads to spatial statistical uncertainty and inadequacy in valuating LUFs, which limits the practical application of LUFs evaluations. Thirdly, although the methods for calculating physical quantities of ecological functions are mature, the calculations of their values, especially for multiple periods, are still scarce, which is a challenge in the study of ecological function value assessment [54]. As a result, each function is calculated by two indicators in this paper, however, the values of aesthetics, recreation, and biodiversity are not included because of lacking detailed data, which may undervalue ecological space. Going forward, simultaneous quantification of multiple LUFs should be strengthened, and more attention should be paid to: on the one hand, understand the role of land resources in economic activities and spatial development, and on the other hand, to deal with inaccurate indicator information by using high-precision spatial data and more stable market price data.

\section{Conclusions}

This study took Zhangjiakou City as an example to map the LUFs value in 1990, 2000, and 2015. Diversity and dominance of LUFs were explored on the basis of the characteristics of LUFs value changes. Our results reveal that the analysis of LUFs value and their evolutionary patterns by fusing multi-source data is an effective way for LUFs coordination and adaptive land use management. The results show that the total value of economic, social, and ecological LUFs continuously increased between 1990 and 2015. The value increase in social function was the most notable, while in ecological function it was the least. There are some obvious spatial differences of both socioeconomic functions and ecological function in Zhangjiakou City. For economic and social functions, their high-value areas were concentrated in the central Yanghe Valley, while the low-value areas were primarily distributed in the eastern and southeastern hilly areas. Ecology function showed an opposite pattern to that of economy and society functions. The diversity of LUFs in Zhangjiakou City in 1990-2015 increased. The functional combination of ELP-ENS-ST accounted for the largest proportion in 1990-2000, and that of SP-ENS-ELT dominated overwhelmingly in 2000-2015. Although the social and economic LUFs began to increase during 1990-2000, the ecological function was dominant, while by 2015, the social function took the lead.

Existing analytical frameworks have attempted to identify and classify land use functions $[4,15,20]$, which has improved our knowledge of the contribution of land use in providing goods and services and meeting human development needs. However, different approaches to LUFs assessment remained fragmented and ignored the value proposition. In this paper, we developed an integrated framework from the perspective of "demandfunction-value" to grasp the internal connection of anthropic value orientation and LUFs' supply. This paper has attempted to apply this framework to Zhangjiakou City, not only achieving good results but also providing a scientific reference for the multifunctional and sustainable land use in this city and other similar areas. It is important to note that different areas will have different development needs, functional definitions, thresholds, and data availability. Future research, therefore, should be developed in two directions: firstly, selecting indicators that are consistent with regional characteristics to better assess local functional land use values. Secondly, enhancing the understanding of the mechanism of LUFs value based on case studies and revealing the dynamics of LUFs value in various typical regions.

Author Contributions: C.L.: conceptualization, methodology, formal analysis, writing-original draft and funding acquisition; Y.X.: joint first author, conceptualization, investigation, resources, writing - review and editing and funding acquisition; Y.W.: conceptualization, writing-review and editing, and supervisions; L.C.: writing—review and editing, and supervision; X.L.: writing-review and editing, and supervision; and Q.Y.: writing-review and editing, and data curation. All authors have read and agreed to the published version of the manuscript. 
Funding: This work was funded by [National Natural Science Foundation of China], grant number [No. 42101282 and No. 41971238].

Institutional Review Board Statement: Not applicable.

Informed Consent Statement: Not applicable.

Data Availability Statement: Data presented in this work are available on request from the first author.

Conflicts of Interest: The authors declare no conflict of interest.

\section{References}

1. Long, H.L.; Qu, Y. Land use transitions and land management: A mutual feedback perspective. Land Use Policy 2018, 74, 111-120. [CrossRef]

2. Lin, G.; Fu, J.; Jiang, D. Production-living-ecological conflict identification using a multiscale integration model based on spatial suitability analysis and sustainable development evaluation: A case study of Ningbo, China. Land 2021, 10, 383. [CrossRef]

3. Huang, J.C.; Lin, H.X.; Qi, X.X. A literature review on optimization of spatial development pattern based on ecological-productionliving space. Prog. Geogr. 2017, 36, 378-391.

4. Pérez-Soba, M.; Petit, S.; Jones, L.; Bertrand, N.; Briquel, V.; Omodei-Zorini, L.; Contini, C.; Helming, K.; Farrington, J.H.; Mossello, M.T.; et al. Land use functions-A multifunctionality approach to assess the impact of land use change on land use sustainability. In Sustainability Impact Assessment of Land Use Changes; Helming, K., Pérez-Soba, M., Tabbush, P., Eds.; Springer: Berlin/Heidelberg, Germany, 2008; pp. 375-404.

5. Gaodi, X.; Lin, Z.; Caixia, Z.; Xiangzheng, D.; Koenig, H.J.; Tscherning, K.; Helming, K. Assessing the multifunctionalities of land use in China. J. Resour. Ecol. 2010, 1, 311-318.

6. Fan, Y.; Jin, X.; Gan, L.; Jessup, L.H.; Pijanowski, B.C.; Yang, X.; Xiang, X.; Zhou, Y. Spatial identification and dynamic analysis of land use functions reveals distinct zones of multiple functions in eastern China. Sci. Total Environ. 2018, 642, 33-44. [CrossRef]

7. Yang, Y.Y.; Bao, W.K.; Liu, Y.S. Coupling coordination analysis of rural production-living-ecological space in the Beijing-TianjinHebei region. Ecol. Indic. 2020, 107, 106512. [CrossRef]

8. Liang, X.; Gu, Z.; Lei, M.; Wang, X. The differences between land use function and land use to reflecting the change of land use system and their impacts on landscape pattern-A case study of Lantian County in Shaanxi Province, China. J. Natur. Resour. 2014, 29, 1127-1135.

9. Dai, W.; Jiang, F.; Huang, W.; Liao, L.; Jiang, K. Study on transition of land use function and ecosystem service value based on the conception of production, living and ecological space-A case study of the Fuzhou New Area. J. Natur. Resour. 2018, 33, 2098-2109.

10. Zhang, L.L.; Zheng, X.Q.; Yuan, Z.Y.; Cui, H.N. Assessment on multi-functionality of land use based on the entire-array-polygon indictor method in Tangshan. China Land Sci. 2016, 30, 23-32.

11. Zhou, D.; Xu, J.C.; Lin, Z.L. Conflict or coordination? Assessing land use multi-functionalization using production-living-ecology analysis. Sci. Total Environ. 2017, 577, 136-147. [CrossRef]

12. Liu, Y.L.; Liao, H.P.; Li, J.; Cai, J.; Li, T.; Wang, Q. Analysis of characteristics and influencing factors of multi-functional spatial pattern of land use in ecological frangible regions. China Land Sci. 2020, 34, 75-83.

13. Duan, J.N.; Liu, S.H.; Li, P.; Yang, W. Study on Research Progress and Directions of Land Functions. China Land Sci. 2020, 34, 8-16.

14. Meng, J.J.; Wang, Q.; Li, F.; Kuo, L. Assessing multifunctional land use in the middle reach of the Heihe River basin based on spatial variances. Geogr. Res. 2019, 38, 369-382.

15. Liu, C.; Xu, Y.Q.; Huang, A.; Liu, Y.X.; Wang, H.; Lu, L.L.; Sun, P.L.; Zheng, W.R. Spatial identification of land use multifunctionality at grid scale in farming-pastoral area: A case study of Zhangjiakou City, China. Habitat Int. 2018, 76, 48-61. [CrossRef]

16. Ouyang, Z.; Song, C.; Zheng, H.; Polasky, S.; Xiao, Y.; Bateman, I.J.; Liu, J.; Ruckelshaus, M.; Shi, F.; Xiao, Y.; et al. Using gross ecosystem product (GEP) to value nature in decision making. Proc. Natl. Acad. Sci. USA 2020, 117, 14593-14601. [CrossRef]

17. Costanza, R.; D’arge, R.; De Groot, R.S.; Farber, S.; Grasso, M.; Hannon, B.; Limburg, K.; Naeem, S.; O'neill, R.V.; Paruelo, J.; et al. The value of the world's ecosystem services and natural capital. Nature 1997, 387, 253-260. [CrossRef]

18. Bernués, A.; Rodríguez-Ortega, T.; Ripoll-Bosch, R.; Alfnes, F. Socio-cultural and economic valuation of ecosystem services provided by mediterranean mountain agroecosystems. PLoS ONE 2014, 9, e102479.

19. Hou, M.Y.; Yao, S.B.; Deng, Y.J.; Ding, Z.M.; Lu, Y.N.; Zheng, X.; Li, Y.N. Spatial-temporal evolution pattern and differentiation of ecological service value in Yan'an city at the grid scale based on Sloping Land Conversion Program. J. Natur. Resour. 2019, 34, 539-552. [CrossRef]

20. Wang, C.; Zhen, L. A comparative assessment of land use functions based on perceptions of policy makers and local farmers in Guyuan, western China. J. Natur. Resour. 2017, 8, 232-241.

21. Ying, H.; Li, Y.B. Land use functions dynamics pattern of Caotangxi watershed in the three gorges reservoir area. Resour. Environ. Yangtze Basin 2017, 26, 227-236.

22. Xue, Z.; Zhen, L.; Md Giashuddin, M.; Kikuko, S. Impact assessment of land use functions on the sustainable regional development of representative Asian countries: A comparative study in Bangladesh, China and Japan. Sci. Total Environ. 2019, 694, 133689. [CrossRef] [PubMed] 
23. Paracchini, M.L.; Pacini, C.; Jones, M.L.M.; Pérez-Soba, M. An aggregation framework to link indicators associated with multifunctional land use to the stakeholder evaluation of policy options. Ecol. Indic. 2011, 11, 71-80. [CrossRef]

24. Wang, F.; Dong, Y.X. Spatial differences and influencing factors of land use function in Guangzhou. Resour. Sci. 2015, 37, 2179-2192.

25. Sun, P.L.; Xu, Y.Q.; Liu, Q.G.; Liu, C.; Huang, A. Spatiotemporal differentiation and driving factors of multi-functionality of land use in county scale in poverty belt around Beijing and Tianjin. Trans. Chin. Soc. Agr. Eng. 2017, 33, $283-292$.

26. Peng, J.; Hu, X.X.; Qiu, S.J.; Hu, Y.N.; Meersmans, J.; Liu, Y.X. Multifunctional landscapes identification and associated development zoning in mountainous area. Sci. Total Environ. 2019, 660, 765-775. [CrossRef]

27. Zhang, Y.N.; Long, H.L.; Tu, S.S.; Ge, D.Z.; Ma, L. Spatial identification of land use functions and their tradeoffs/synergies in China: Implications for sustainable land management. Ecol. Indic. 2019, 107, 105550. [CrossRef]

28. Lester, S.E.; Costello, C.; Halpern, B.S.; Gaines, S.D.; White, C.; Barth, J.A. Evaluating tradeoffs among ecosystem services to inform marine spatial planning. Mar. Policy 2013, 38, 80-89. [CrossRef]

29. Lin, A.W.; Zhan, X.; Peng, Y.L.; Xia, Y.; Yue, B.J.; Qin, W.J. Study on functional zoning of land use in the Greater Mekong Sub-region: A case study of central Laos. Geomat. Spat. Inf. Technol. 2016, 39, 1-5.

30. Wiggering, H.; Dalchow, C.; Glemnitz, M.; Helming, K.; Müller, K.; Schultz, A.; Stachow, U.; Zander, P. Indicators for multifunctional land use: Linking socio-economicrequirements with landscape potentials. Ecol. Indic. 2006, 6, 238-249. [CrossRef]

31. Zou, L.; Liu, Y.; Yang, J.; Yang, S.; Wang, Y.; Hu, X. Quantitative identification and spatial analysis of land use ecologicalproduction-living functions in rural areas on China's southeast coast. Habitat Int. 2020, 100, 102182. [CrossRef]

32. Zhen, L.; Cao, S.Y.; Wei, Y.J.; Xie, G.D.; Li, F.; Li, Y. Land use functions: Conceptual framework and application for China. Resour. Sci. 2009, 31, 544-551.

33. Liu, C.; Xu, Y.Q.; Sun, P.L.; Huang, A.; Zheng, W.R. Land use change and its driving forces toward mutual conversion in Zhangjiakou City, a farming-pastoral ecotone in Northern China. Environ. Monit. Assess. 2017, 189, 505. [CrossRef] [PubMed]

34. Wang, J.L.; Sun, J.L. Some in-depth thoughts on resources and environmental comprehensive scientific expedition using gridding approach in China. J. Geogr. Inf. Sci. 2015, 17, 758-764.

35. Zhang, J.; Wu, S.H.; Liu, Y.H.; Yang, Q.Y.; Zhang, Y.H. Simulation of distribution of agricultural output value influenced by land use and topographical indices in Tibet. Trans. Chin. Soc. Agr. Eng. 2007, 23, 59-65.

36. Dai, Z.; Hu, Y.; Zhao, G. The suitability of different nighttime light data for GDP estimation at different spatial scales and regional levels. Sustainability 2017, 9, 305. [CrossRef]

37. Zhao, M.; Cheng, W.M.; Zhou, C.H.; Li, M.C.; Wang, N.; Liu, Q.Y. GDP spatialization and economic differences in south China based on NPP-VIIRS nighttime light imagery. Remote Sens. 2017, 9, 673. [CrossRef]

38. Taelman, S.E.; Schaubroeck, T.; De Meester, S.; Boone, L.; Dewulf, J. Accounting for land use in life cycle assessment-The value of NPP as a proxy indicator to assess land use impacts on ecosystems. Sci. Total Environ. 2016, 550, 143-156. [CrossRef]

39. Kong, X.B.; Lin, J.; Wang, J.; Li, Q.F.; Sun, Y.W. Impacts of productive ratio coefficient on grade of farmland classification. Trans. Chin. Soc. Agr. Eng. 2009, 25, 237-243.

40. Tan, M.; Li, X.; Li, S.; Xin, L.; Wang, X.; Li, Q.; Li, W.; Li, Y.; Xiang, W. Modeling population density based on nighttime light images and land use data in China. Appl. Geogr. 2018, 90, 239-247. [CrossRef]

41. Liu, X.F.; Ren, Z.Y.; Lin, Z.H. Dynamic assessment of the values of $\mathrm{CO}_{2}$ fixation and $\mathrm{O}_{2}$ release in Qinghai-Tibet Plateau ecosystem. Geogr. Res. 2013, 32, 663-670.

42. Zhang, C.; Ren, Z.Y. Dynamic evaluation of the value of carbon fixation and oxygen release based on land ecosystem in Northern Shaanxi. Geogr. Res. 2015, 34, 1522-1534.

43. Huang, A.; Xu, Y.; Sun, P.; Zhou, G.; Liu, C.; Lu, L.; Xiang, Y.; Wang, H. Land use/land cover changes and its impact on ecosystem services in ecologically fragile zone: A case study of Zhangiiakou City, Hebei Province, China. Ecol. Indic. 2019, 104, 604-614. [CrossRef]

44. Han, Y.W.; Gao, J.X.; Wang, B.L.; Liu, C.C.; Wang, J.; Tuo, X.S. Evaluation of soil conservation function and its values in major eco-function areas of Loess Plateau in eastern Gansu province. Trans. Chin. Soc. Agr. Eng. 2012, 28, 78-85.

45. Kumar, A.; Devi, M.; Deshmukh, B. Integrated remote sensing and geographic information system based RUSLE modelling for estimation of soil loss in Western Himalaya, India. Water Resour. Manag. 2014, 28, 3307-3317. [CrossRef]

46. Gao, J.B.; Zhou, Q.F.; Chang, Q.; Li, S.C. Evaluating the ecological service function of soil conservation based on RUSLE and GIS. Acta Sci. Nat. Univ. Pekin. 2009, 45, 151-157.

47. Li, J.; Ren, Z.Y. Variations in ecosystem service value in response to land use changes in the Loess Plateau in northern Shaanxi province, China. Int. J. Environ. Res. 2011, 5, 109-118.

48. Zhang, N.X. A study on inflation rate and the moderate range of economic growth: Based on the analysis of GDP deflator index. Price Theory Pract. 2019, 1, 83-87.

49. Duan, Y.M.; Wang, H.; Huang, A.; Xu, Y.Q.; Lu, L.H.; Ji, Z.X. Identification and spatial-temporal evolution of rural "productionliving-ecological" space from the perspective of villagers' behavior: A case study of Ertai Town, Zhangjiakou City. Land Use Policy 2021, 106, 105457. [CrossRef]

50. Fan, J. Spatial organization pathway for territorial function-structure: Discussion on implementation of major function zoning strategy in territorial spatial planning. Geogr. Res. 2019, 38, 2373-2387. 
51. Tu, S.S.; Long, H.L.; Zhang, Y.N.; Ge, D.Z.; Qu, Y. Rural restructuring at village level under rapid urbanization in metropolitansuburbs of China and its implications for innovations in land use policy. Habitat Int. 2018, 77, 143-152. [CrossRef]

52. Hartmann, T.; Jehling, M. From diversity to justice: Unraveling pluralistic rationalities in urban design. Cities 2019, 91, 58-63. [CrossRef]

53. Verburg, P.H.; van de Steeg, J.; Veldkamp, A.; Willemen, L. From land cover change to land function dynamics: A major challenge to improve land characterization. J. Environ. Manag. 2009, 90, 1327-1335. [CrossRef] [PubMed]

54. Maes, J.; Paracchini, M.L.; Zulian, G. A European Assessment of the Provision of Ecosystem Services-Towards an Atlas of Ecosystem Services; EUR, Publications Office of the European Union: Luxembourg, 2011. [CrossRef] 